\title{
Jones matrix mapping of polycrystalline networks of layers of main types of amino acids
}

\section{Volodymyr D. Mishalov, Viktor T. Bachinsky, Oleg Ya. Vanchuliak, Alina Y. Zavolovitch, Yuliya V. Sarkisova, et al.}

Volodymyr D. Mishalov, Viktor T. Bachinsky, Oleg Ya. Vanchuliak, Alina Y. Zavolovitch, Yuliya V. Sarkisova, Alexander G. Ushenko, Sergii V. Pavlov, Olexander V. Dubolazov, Vladimir A. Ushenko, Artem V. Motrich, Yaroslav M. Drin, Andrzej Kociubiński, Mashat Kalimoldayev, "Jones matrix mapping of polycrystalline networks of layers of main types of amino acids," Proc. SPIE 11176, Photonics Applications in Astronomy, Communications, Industry, and High-Energy Physics Experiments 2019, 1117606 (6 November 2019); doi: $10.1117 / 12.2536245$ 


\title{
Jones matrix mapping of polycrystalline networks of layers of main types of amino acids
}

\author{
Volodymyr D. Mishalov*a, Viktor.T. Bachinsky ${ }^{\mathrm{b}}$, Oleg Ya. Vanchulyak ${ }^{\mathrm{b}}$, Alina Y. Zavolovitch ${ }^{\mathrm{b}}$, \\ Yuliya V. Sarkisova ${ }^{b}$, Alexander G. Ushenkoc, Sergii V. Pavlov ${ }^{\mathrm{d}}$, Olexander V. Dubolazov ${ }^{\mathrm{c}}$, \\ Vladimir A. Ushenko ${ }^{c}$, Artem V. Motrich ${ }^{c}$, Yaroslav M. Drin ${ }^{c}$, Andrzej Kociubiński ${ }^{\mathrm{e}}$, Mashat \\ Kalimoldayev ${ }^{\mathrm{f}}$ \\ a Shupyk National Medical Academy of Postgraduate Education, 9, Dorogozhytska St., Kyiv, 04112, \\ Ukraine; 'bukovinian State Medical University, Teatral'na Square, 2, 58000 Chernivtsi, Ukraina; \\ ${ }^{\mathrm{c} C h e r n i v t s i}$ National University, Kotsyubynsky 2, 58012 Chernivtsi, Ukraine; ${ }^{\mathrm{d}}$ Vinnytsia National \\ Technical University, Khmel'nyts'ke Hwy, 95, 21000 Vinnytsia, Ukraina; ${ }^{\mathrm{E}}$ Lublin University of \\ Technology, Nadbystrzycka 38D, 20-618 Lublin, Poland; ${ }^{f}$ Institute of Information and \\ Computational Technologies CS MES RK, 050010 Almaty, 125 Pushkina,Republic of Kazakhstan
}

\begin{abstract}
The given data on the optical arrangement, in which the coordinate distributions of the real and imaginary component of the elements of the Jones matrix of optically thin polycrystalline layers are determined. Algorithms are presented and an experimental method for measuring the real and imaginary component of Jones-matrix images is analyzed. The experimental results of the study of statistical, correlation, and fractal parameters, which characterize the real component of the Jones-matrix image of polycrystalline networks of flat layers of the main types of human amino acids, are presented.
\end{abstract}

Keywords: polarization, interference, anisotropy, cartography

\section{INTRODUCTION}

The actual direction in laser polarimetric diagnostics [1-11] of biological objects is the development of matrix methods [12-15], which provide the most complete information about the polycrystalline structure [16-21] of films of biological fluids of human organs. We study possibilities of the development and experimental testing of the Jones matrix (JM) mapping method for polycrystalline layers of basic amino acids of the human body in order to obtain parameters for the differential diagnosis of pathological conditions.

\section{POLARIZATION DEVICE FOR JONES-MATRIX MAPPING OF AMINO ACID FILMS}

Figure 1 illustrates the device scheme of polarization cartography of the coordinate distributions of the real and imaginary components of the Jones matrix of biological fluids. The illumination was carried out in parallel $(\varnothing=104 \mu \mathrm{m})$ by a coherent beam $(\lambda=0.6328 \mu \mathrm{m}, \mathrm{W}=5.0 \mathrm{~mW})$. The illuminator part include phase shift plates 3; 5 and linear polarizer 4. Polarization images of biological samples were projected by micro-lens 7 (magnification $4 \mathrm{x}$ ) on to the photosensitive area of a CCD camera 10. Polarization analysis of biological samples of microscopic images of fluids was carried out using a analyzer 9 and a phase shift plate 8.

* a.dubolazov@chnu.edu.ua

Photonics Applications in Astronomy, Communications, Industry, and High-Energy Physics Experiments 2019,

edited by Ryszard S. Romaniuk, Maciej Linczuk, Proc. of SPIE Vol. 11176, 1117606

(C) 2019 SPIE · CCC code: 0277-786X/19/\$21 - doi: 10.1117/12.2536245 


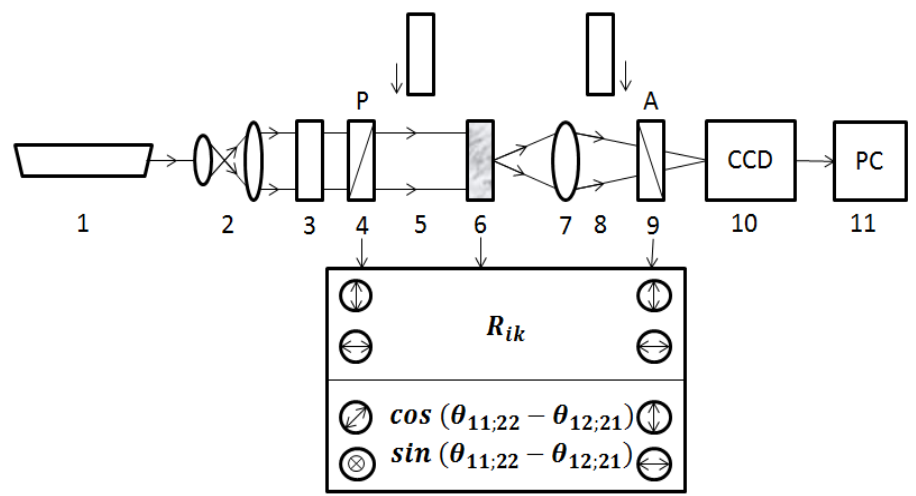

Figure 1. The optical scheme of the polarimeter, where 1 - He-Ne laser; 2 - collimator; 3,5,8 - phase shift plates; 4, 9 - polarizers; 6 - sample; 7 - micro lens; 10 - CCD camera; 11 - personal computer

\section{POLARIZATION IMAGES OF ANISOTROPIC STRUCTURE OF AMINO ACIDS}

We carried out a comprehensive study of the real component of the maps of the elements of the polarization matrix (PM) $R_{11}(m \times n)$ and $R_{12 ; 21}(m \times n)$, characterizing mainly the manifestations of the orientational $\rho$ and phase $\delta$ structure of an ensemble of liquid amino acid crystals. Figure 2 shows a series of polarization images of the crystalline layers of the main types of amino acids of the human body.

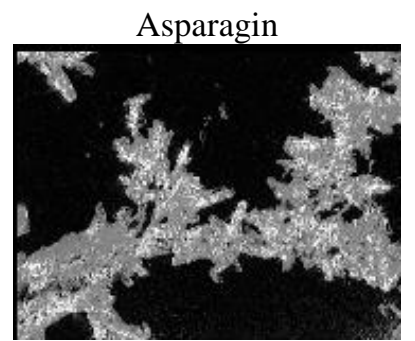

Glutamine

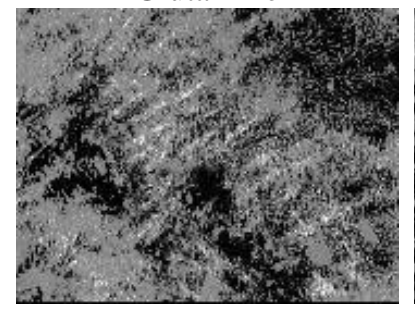

Proline

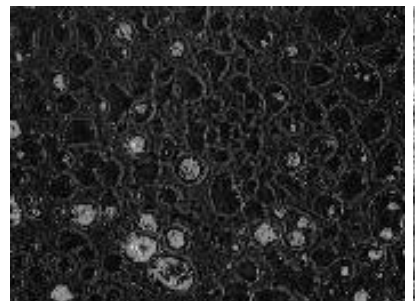

Cysteine

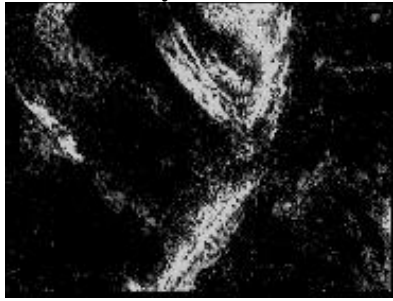

Isoleucine

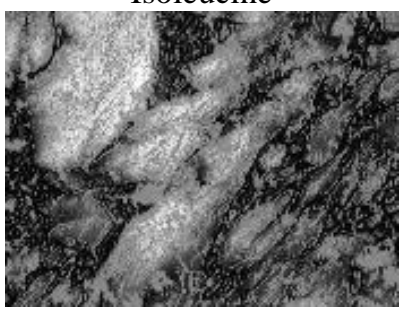

Threonine

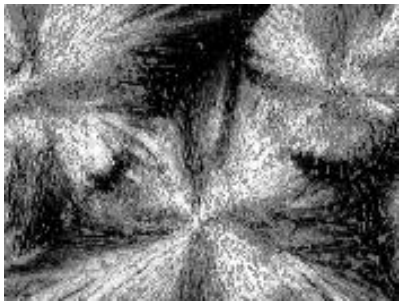

Glycine

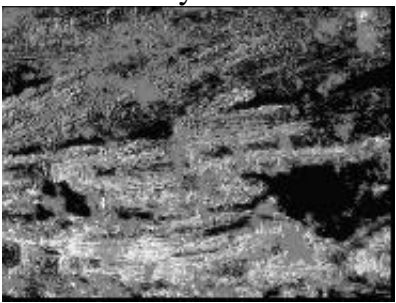

Methionine

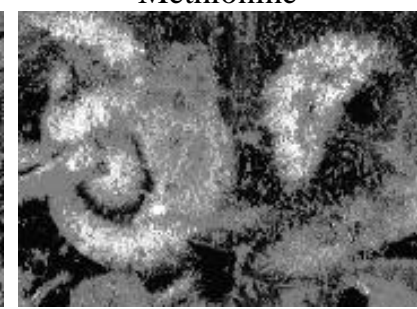

Tryptophan

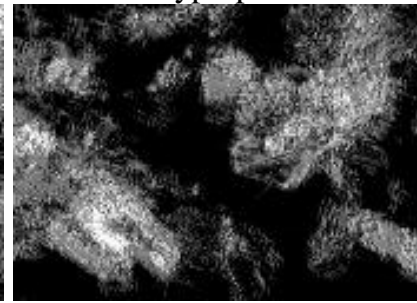

Globulin

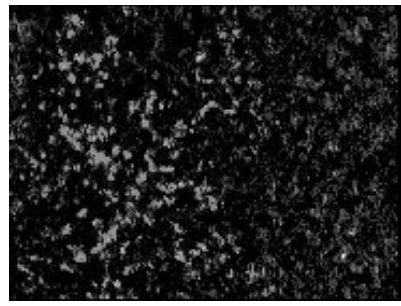

Ornithine

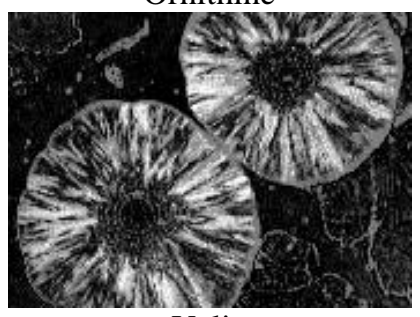

Valin

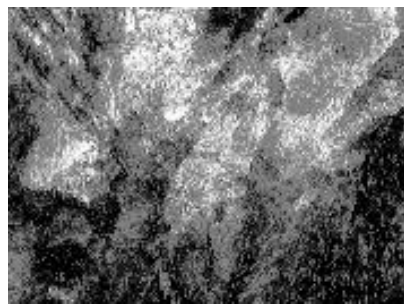

Figure 2. Polycrystalline networks of basic types of human amino acids

Figures 3 to 8 show the Jones-matrix images of the real component of the “orientation" $R_{11}(m \times n)$ and “phase” $R_{12 ; 21}(m \times n)$ maps and three-dimensional reconstructions of their values $N\left(R_{11}\right), N\left(R_{12 ; 21}\right)$, autocorrelation functions $G_{11}(\Delta x) ; G_{12 ; 21}(\Delta x)$, logarithmic spectral dependences $\operatorname{LgJ}\left(G_{11}\right) ; \operatorname{LgJ}\left(G_{12 ; 21}\right)$ of maps of the real 
component of the JM elements of glycine amino acids (Fig. 3 and Fig. 4), methionine (Fig. 5 and Fig. 6) and proline (Fig. 7 and Fig. 8), respectively.

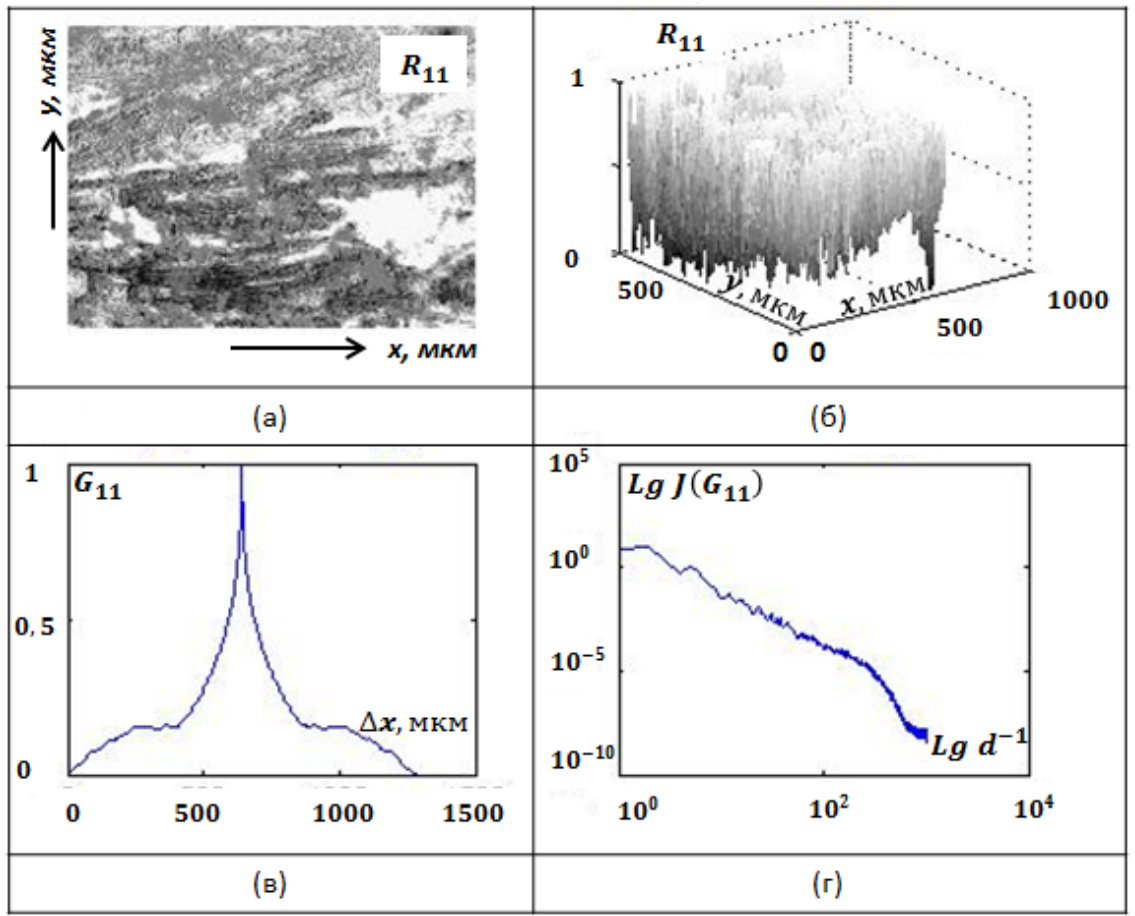

Figure 3. Maps (a), probabilistic (b), autocorrelation (c) and self-similar (d) characteristics of the actual component of the JM element $R_{11}$ of a PS of a glycine layer

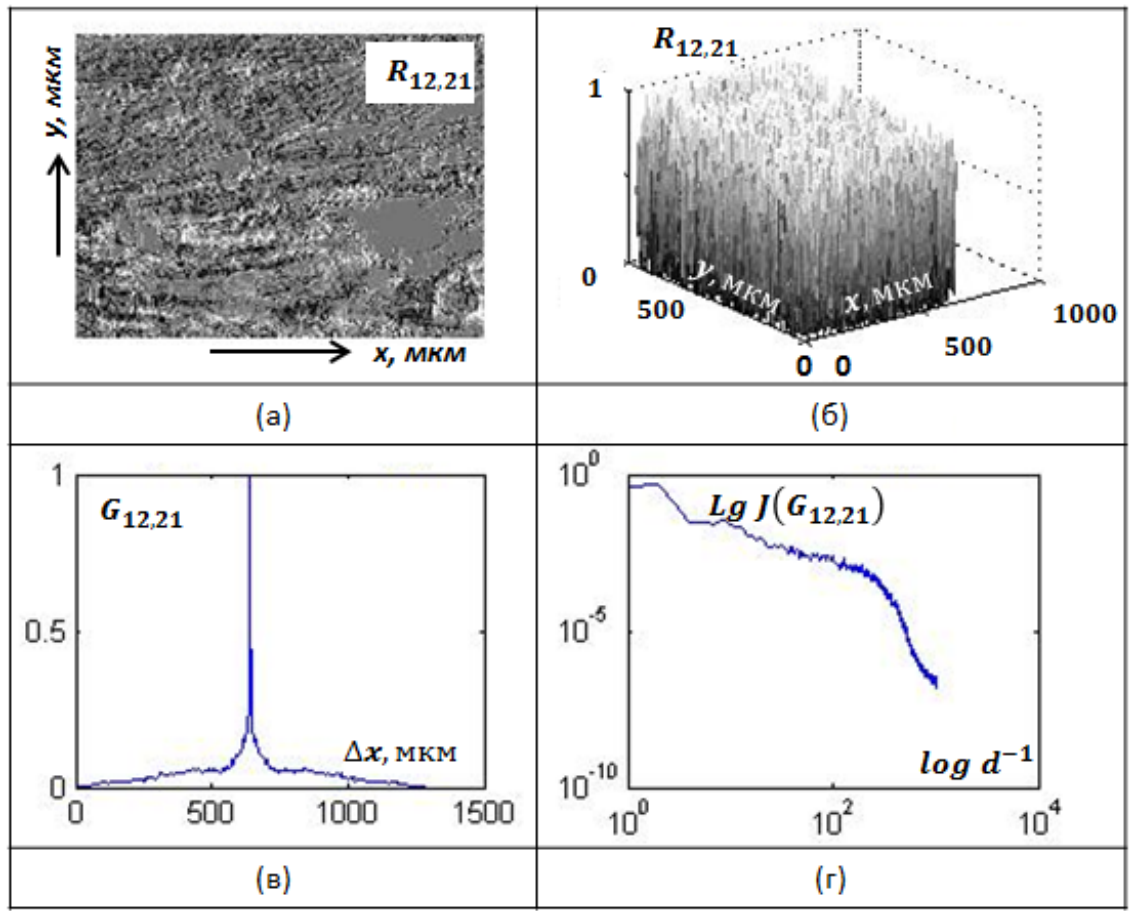

Figure 4. Maps (a), probabilistic (b), autocorrelation (c) and self-similar (d) characteristics of the actual component of the JM element $R_{12 ; 21}$ of the PS of the glycine layer 


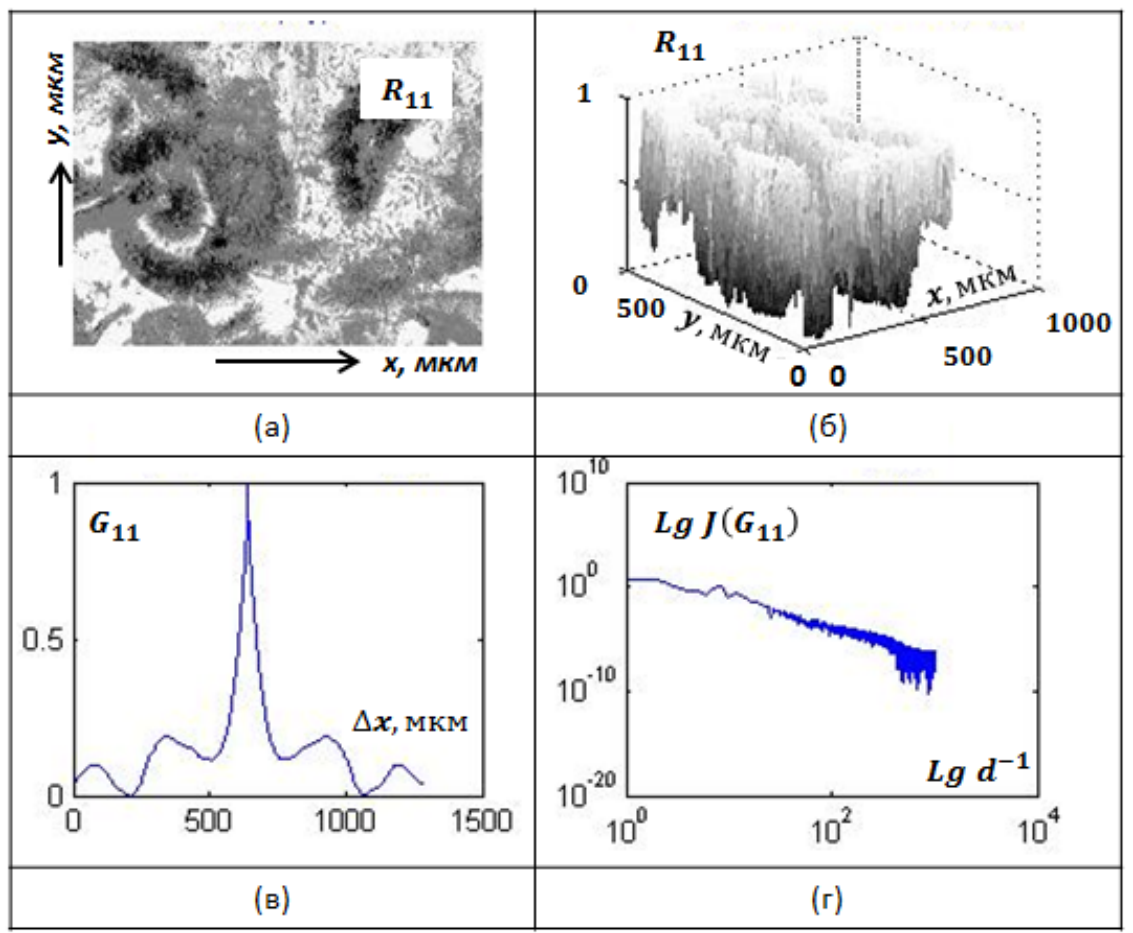

Figure 5. Coordinate (a), probabilistic (b), correlation (c) and self-similar (d) structure of the real component of the element of the Jones matrix $\mathrm{R}_{11}$ of the polycrystalline network of a mitionine layer

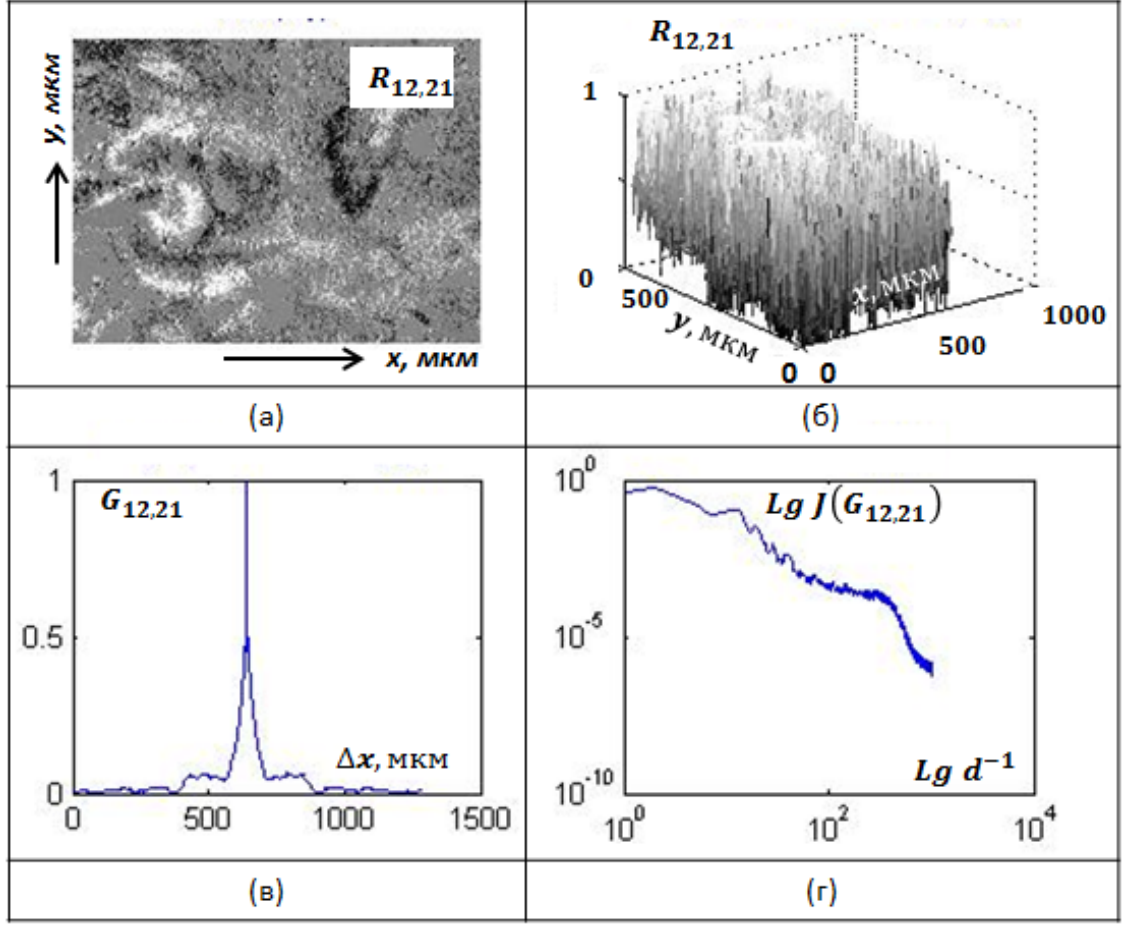

Figure 6. Coordinate (a), probabilistic (b), correlation (c) and self-similar (d) structure of the actual component of the element of the Jones matrix $\mathrm{R}_{12 ; 21}$ of the polycrystalline network of the mitionine layer 


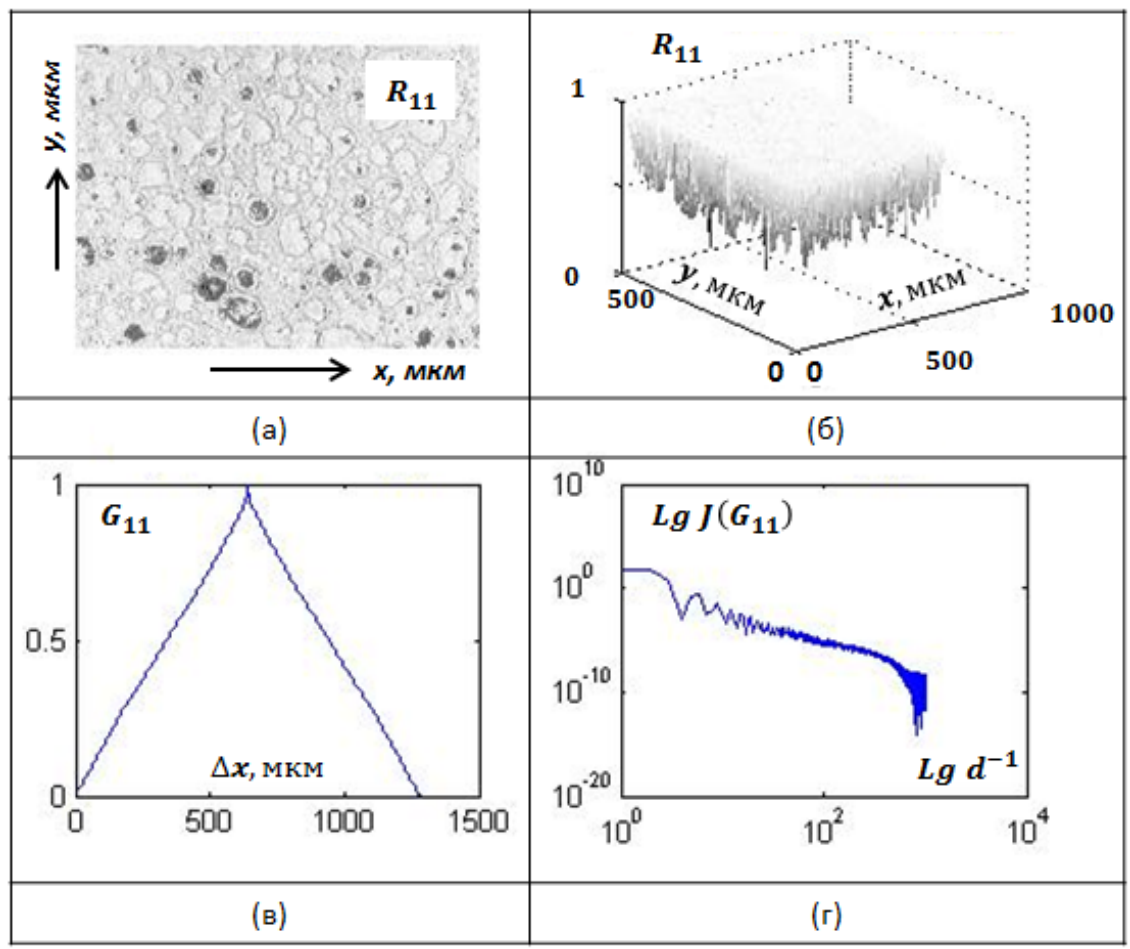

Figure 7. Maps (a), probabilistic (b), autocorrelation (c) and self-similar (d) characteristics of the actual component of the JM element $R_{11}$ of a PS of a proline layer

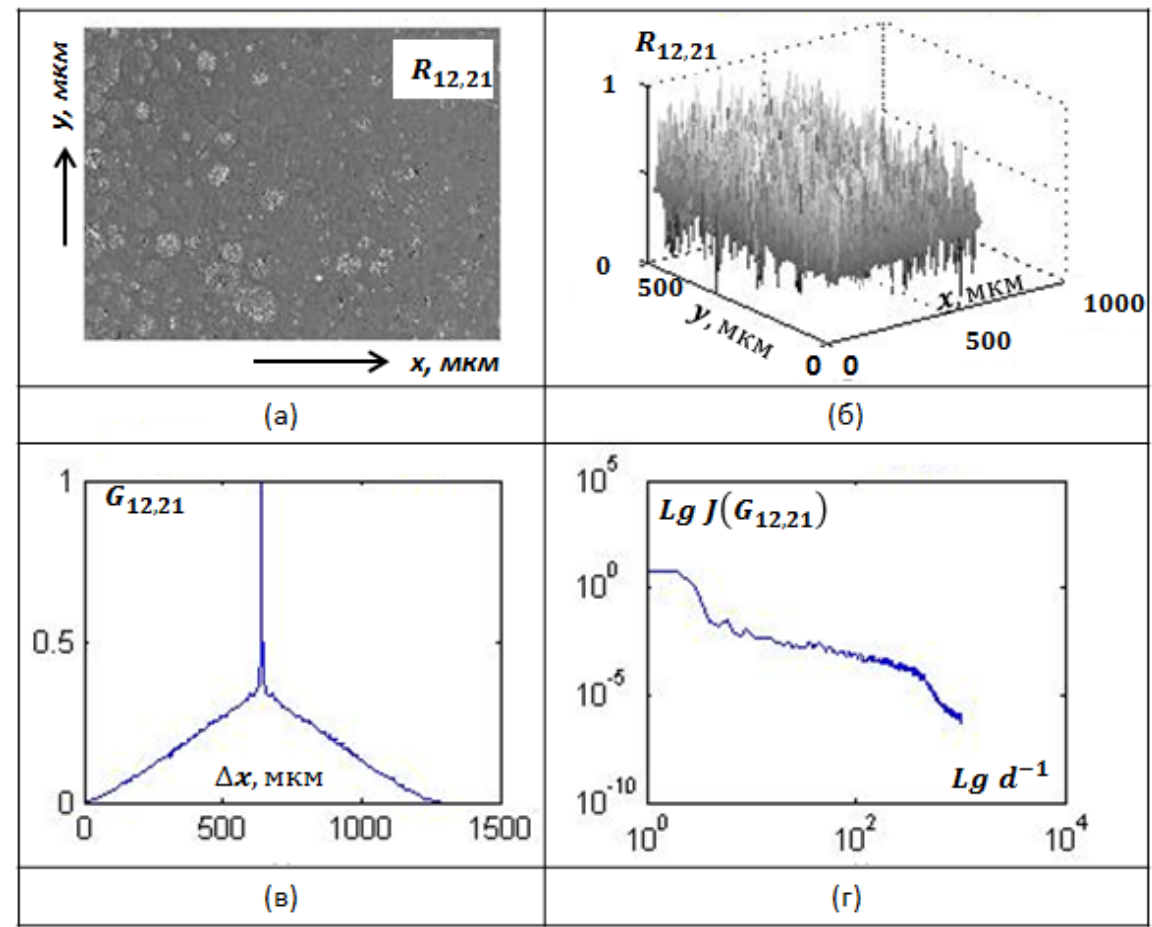

Figure 8. Maps (a), probabilistic (b), autocorrelation (c) and self-similar (d) characteristics of the actual component of the JM element $R_{12 ; 21}$ of a PS of a proline layer 
1. The space structure of the angles of the crystal axes of the PS of amino acids has a significant effect. We measured a wide range of value changes $\left(0 \leq \Delta R_{11} \leq 1\right)$ in the maps $R_{11}(m \times n)$ (Fig. 3, Fig. 5, Fig. 7 Fragments (a)). Moreover, all maps of the real component of the "orientational" elements of the JM are individual (Fig. 3, Fig. .5, Fig. 7. Fragments (b)).

2. The differences between the maps of the real component of the "phase" $R_{12 ; 21}$ element (Fig. 4, Fig. 6, Fig. 8, fragments (a)) of PS amino acid are not so expressive (Fig. 4, Fig. 6, Fig. 8 Fragments (b)) as for JM distributions of "orientation" elements.

3. The autocorrelation functions $G_{11 ; 12 ; 1}(\Delta x)$ of the maps of the real component of the JM elements biological layers with dendritic and spherolitic geometry are falling dependencies with modulations of eigenvalues (Fig. 3 and Fig. 5 fragments (c)).

4. The real component $R_{12 ; 21}(m \times n)$ are practically fractal; for the "phase" matrix element - multifractal. The corresponding logarithmic dependences $\operatorname{LgJ}\left(G_{11}\right)$ are characterized by a constant angle of inclination (Fig. 3, Fig. 5 and Fig. 7, fragments (d)). Dependencies $\operatorname{LgJ}\left(G_{12 ; 21}\right)$ are characterized by broken approximating curves with two angles of inclination (Fig. 4, Fig. 6, and Fig. 8, fragments (d)).

The results of the quantitative analysis of JM maps are shown in Table 1.

Table 1. Statistical, autocorrelation, fractal parameters of JM maps of amino acid samples

\begin{tabular}{|c|c|c|c|c|c|c|c|c|c|c|c|}
\hline \multicolumn{6}{|c|}{$R_{11}(m \times n)$} & \multicolumn{6}{|c|}{$R_{12 ; 21}(m \times n)$} \\
\hline \multicolumn{12}{|c|}{ Glycine } \\
\hline$M$ & 0,41 & $K_{1}$ & 0,44 & $S_{1}$ & 0,56 & $M$ & 0,46 & $K_{1}$ & 0,48 & $S_{1}$ & 0,53 \\
\hline$\sigma$ & 0,21 & $K_{2}$ & 0,14 & $S_{2}$ & 0,19 & $\sigma$ & 0,19 & $K_{2}$ & 0,14 & $S_{2}$ & 0,14 \\
\hline A & 0,86 & $K_{3}$ & 1,31 & $S_{3}$ & 0,62 & A & 0,24 & $K_{3}$ & 0,29 & $S_{3}$ & 0,43 \\
\hline$E$ & 0,63 & $K_{4}$ & 3,16 & $S_{4}$ & 0,83 & $E$ & 0,17 & $K_{4}$ & 1,19 & $S_{4}$ & 0,37 \\
\hline \multicolumn{12}{|c|}{ Methionine } \\
\hline$M$ & 0,31 & $K_{1}$ & 0,52 & $S_{1}$ & 0,48 & $M$ & 0,51 & $K_{1}$ & 0,51 & $S_{1}$ & 0,5 \\
\hline$\sigma$ & 0,15 & $K_{2}$ & 0,11 & $S_{2}$ & 0,13 & $\sigma$ & 0,24 & $K_{2}$ & 0,11 & $S_{2}$ & 0,11 \\
\hline A & 0,53 & $K_{3}$ & 0,57 & $S_{3}$ & 0,47 & $A$ & 0,18 & $K_{3}$ & 0,24 & $S_{3}$ & 0,31 \\
\hline$E$ & 0,68 & $K_{4}$ & 2,12 & $S_{4}$ & 0,39 & $E$ & 0,12 & $K_{4}$ & 0,91 & $S_{4}$ & 0,27 \\
\hline \multicolumn{12}{|c|}{ Proline } \\
\hline$M$ & 0,39 & $K_{1}$ & 0,45 & $S_{1}$ & 0,56 & $M$ & 0,48 & $K_{1}$ & 0,48 & $S_{1}$ & 0,52 \\
\hline$\sigma$ & 0,28 & $K_{2}$ & 0,1 & $S_{2}$ & 0,13 & $\sigma$ & 0,32 & $K_{2}$ & 0,07 & $S_{2}$ & 0,09 \\
\hline$A$ & 0,12 & $K_{3}$ & 0,24 & $S_{3}$ & 0,48 & $A$ & 0,12 & $K_{3}$ & 0,36 & $S_{3}$ & 0,21 \\
\hline$E$ & 0,09 & $K_{4}$ & 1,38 & $S_{4}$ & 0,27 & E & 0,09 & $K_{4}$ & 1,15 & $S_{4}$ & 0,18 \\
\hline
\end{tabular}




\section{CONCLUSIONS}

The entire set of 1st, 4th order statistical moments of probability, autocorrelation and fractal parameters of the real component of the elements of the Jones matrix, has individual sets of values.

The disordering of the orientations of the crystals axes of amino acids is manifested - a decrease in the magnitudes of the statistical moments of the 3rd and 4th orders of the maps of the real component of the "orientation" element of the Jones matrix.

Attenuation of oscillations of the Jones matrix autocorrelation functions, as well as a decrease the values $K_{3}$ and $K_{4}$;

The growth of the 3rd and 4th order spectral moments, which characterize the logarithmic dependences of the power spectra of the Jones matrix maps of the real component of the "orientational" matrix element.

\section{REFERENCES}

[1] Ushenko, V. A., Koval, G. D., Gavrylyak, M. S., Mueller, "Matrices polarization selection of two-dimensional linear and circular birefringence images," Proceedings of SPIE - The International Society for Optical Engineering 8856, 88562E (2013).

[2] Prysyazhnyuk, V. P., Ushenko, Yu. A., Dubolazov, A. V., Ushenko, A. G., Ushenko, V. A., "Polarizationdependent laser autofluorescence of the polycrystalline networks of blood plasma films in the task of liver pathology differentiation," Applied Optics 55(12), B126-B132 (2016).

[3] Ushenko, V. A., "Complex degree of mutual coherence of biological liquids," Proceedings of SPIE - The International Society for Optical Engineering 8882, 88820V (2013).

[4] Ushenko, Y. A., Koval, G. D., Ushenko, A. G., Dubolazov, O. V., Ushenko, V. A., Novakovskaia, O. Y., "Mueller-matrix of laser-induced autofluorescence of polycrystalline films of dried peritoneal fluid in diagnostics of endometriosis," Journal of Biomedical Optics 21(7), 071116 (2016).

[5] Ushenko, V. O., "Spatial-frequency polarization phasometry of biological polycrystalline networks," Optical Memory and Neural Networks (Information Optics) 22(1), 56-64 (2013).

[6] Angelsky, P. O., Ushenko, A. G., Dubolazov, A. V., Sidor, M. I., Bodnar, G. B., Koval, G., Trifonyuk, L., "The singular approach for processing polarization-inhomogeneous laser images of blood plasma layers," Journal of Optics (United Kingdom) 15(4), 044030 (2013).

[7] Ushenko, O. G., Dubolazov, A. V., Balanets'ka, V. O., Karachevtsev, A. V., Sydor, M., "Wavelet analysis for polarization inhomogeneous laser images of blood plasma," Proceedings of SPIE - The International Society for Optical Engineering 8338, 83381H (2011).

[8] Angelsky, O. V., Ushenko, Y. A., Dubolazov, A. V., Telenha, O. Yu., "The interconnection between the coordinate distribution of Mueller-matrixes images characteristic values of biological liquid crystals net and the pathological changes of human tissues," Advances in Optical Technologies, 130659 (2010).

[9] Dubolazov, A. V., Marchuk, V., Olar, O. I., Bachinskiy, V. T., Vanchuliak, O. Ya., Pashkovska, N. V., Andriychuk, D., Kostiuk, S. V., "Multiparameter correlation microscopy of biological fluids polycrystalline networks, " Proceedings of SPIE - The International Society for Optical Engineering 9066, 90661Y (2013).

[10] Wojcik, W.; Bieganski, T.; Kotyra, A.; et al., "Application of algorithms of forecasting in the optical fibre coal dust burner monitoring system: Technology and applications of light guides," Proceedings of the Society of Photo-Optical Instrumentation Engineers (SPIE) 3189, 100-109 (1997).

[11]Wojcik, W., Kotyra, A., Lawicki, T., "A quality factor of combustion of pulverized coal based on image analysis using the curvelet transform," Przeglad Elektrotechniczny 88(10B), 82-84 (2012).

[12] Lach, Z., Smolarz, A., Wojcik, W., et al. "Optically powered system for automatic protection of a fiber segment," Przeglad Elektrotechniczny 84(3), 259-262 (2008).

[13]Koprowski, R., Korzynska, A., Wrobel, Z., et al. "Influence of the measurement method of features in ultrasound images of the thyroid in the diagnosis of Hashimoto's disease," Biomedical Engineering Online 11(91), (2012).

[14]Zyska, T., Wojcik, W., Imanbek, B., et al., "Diagnosis of the thermocouple in the process of gasification of biomass," Rocznik Ochrona Srodowiska 18, 652-666 (2016). 
[15]Timchenko, L. I., Pavlov, S. V., Kokryatskaya, N. I., et al. "Bio-inspired approach to multistage image processing," Photonics Applications in Astronomy, Communications, Industry, and High Energy Physics Experiments 2017, Proceedings of SPIE 10445, UNSP 104453M (2017).

[16]Wojcik, W., Cakala, S., Kotyra, A., et al., "Analysis of the operation of an electrooptical Pockels effect," Technology and Applications of Light Guides, Proceedings of the Society of Photo-Optical Instrumentation Engineers (SPIE) 3189, 110-121 (1997).

[17] Maciejewski, M., Surtel, W., Wojcik, W., et al., "Telemedical systems for home monitoring of patients with chronic conditions in rural environment," Annals of Agricultural and Environmental Medicine 21(1), 167173 (2014).

[18]Smolarz, A., Gromaszek, K., Wojcik, W., et al., "Optical methods and artificial intelligence in diagnostics of industrial pulverized coal burner," Przeglad Elektrotechniczny 88(9B), 259-261 (2012).

[19]Kotyra, A., Wojcik, W., Gromaszek, K., et al., "Assessment of biomass-coal co-combustion on the basis of flame image," Przeglad Elektrotechniczny 88(11B), 295-297 (2012).

[20] Rovira, R. H., Pavlov, S. V., Kaminski, O. S., Bayas, M. M., "Methods of Processing Video Polarimetry Information Based on Least-Squares and Fourier Analysis," Middle-East Journal of Scientific Research 16(9), 1201-1204 (2013).

[21] Zabolotna, N. I., Pavlov, S. V., Ushenko, A. G., Karachevtsev, A. O., Savich, V. O., et al. "System of the phase tomography of optically anisotropic polycrystalline films of biological fluids," Proceedings of SPIE 9166, Biosensing and Nanomedicine VII, 916616 (2014).

[22] Zabolotna, N. I., Pavlov, S. V., Ushenko, A. G., Sobko O. V., Savich, V. O, "Multivariate system of polarization tomography of biological crystals birefringence networks," Proceedings of SPIE 9166, Biosensing and Nanomedicine VII, 916615 (2014). 